Annals of Plant Sciences

\title{
In-vitro antioxidant and anti-inflammatory potential of ethanol extracts (root and aerial parts) of Barleria noctiflora
}

Manjula M. S. ${ }^{*}$ and A. Saravana Ganthi ${ }^{2}$

1P.G. Department of Botany, Adhiyaman Arts and Science College for Women, Uthangarai, Krishnagiri District635207, TN, India.

2P.G. Department of Botany, Rani Anna Govt. College for Women, Tirunelveli- 627008, TN, India.

Received: 12/24/2017; Accepted: 1/3/2018

\begin{abstract}
Barleria noctiflora L.f. (Acanthaceae) is widely used as folk medicine. In the present study ethanol extracts of root and aerial parts of Barleria noctiflora were prepared using soxhlet extractor. Anti-oxidant potential was evaluated by free radical scavenging activity on DPPH and in vitro anti- inflammation activity of the selected samples stood determined by inhibition of protein denaturation experiment and inhibition of $\alpha$-amylase studies. Among the root and aerial parts of Barleria noctiflora samples root sample shows significantly high level of antioxidant and anti-inflammatory activity.
\end{abstract}

Keywords: antioxidant, inflammation, Acanthaceae, Barleria noctiflora

\section{Introduction}

Plant-based drugs have been used against various diseases since a long time. The nature has provided abundant plants which possess medicinal virtues. Therefore, there is a necessity to explore their uses and to conduct pharmacognostic and pharmacological studies to ascertain their therapeutic properties (Ranjit Singh et al., 2012). Plants with antioxidant activities have been reported to possess free radical scavenging activity. Free radicals are known as major contributors to several clinical disorders such as diabetes mellitus, cancer, liver diseases, renal failure and degenerative diseases as a result of deficient natural antioxidant defence mechanism (Yogamoorthi and Sathya Priya, 2004; Wetson et al., 2012; Zeng et al., 2006).

Inflammation is a normal protective response shown by living tissue against the injury caused by physical trauma, noxious chemicals or microbiological agents (Tripathi, 2004; Robert, 2009; Sandhya Lakheda et al., 2011), which removes pathogens or other stimuli and further help to restore cells to normal state or replace damaged tissue with scar (Rashmi et al., 2011) Bacterial infection causes an increased numbers of neutrophills, which leads to the production of oxidative burst at the site of microbial invasion (Saima Jalil et al., 2003). However inflammation remains unchecked, it leads to the onset of diseases such as vasomotor rhinitis and atherosclerosis (Duangporn Premjet et al., 2010).

\footnotetext{
${ }^{*}$ Corresponding Author:

Dr. M. S. Manjula,

Head, P.G. Department of Botany,

Adhiyaman arts and science college for women,

Uthangarai, Krishnagiri district,

Tamil Nadu, India.

E-mail: msmanjulatpm@gmail.com
}

The genus Barleria includes 28 taxa and 26 species. It has 3 unique characters calyx 4 partile with 2 large outer segments and 2 smaller inner ones, spheroidal, honey combed pollen grains and the predominant with double cystoliths (Shankar and Yadav, 2010). Most of the Barleria species are potent anti inflamatory, analgestic, antileukemic, antitumor, antihyperglycemic, anti-amoebic, virudal and antibiotic (Jassim and Naji, 2003; Suba et al., 2004; Suba et al., 2005). Barleria noctiflora L.f. is a shrub and it grows up to $90 \mathrm{~cm}$ height (Madhu et al., 2010). It is being widely used as folk medicine. It is widely distributed throughout tropical region of Africa, India, Srilanka and other parts of Asia (Athar et al., 2009). All parts of the Barleria noctiflora are used to treat diabeties (Marles and Farnsworth, 1995).

\section{Materials and Methods}

Preparation of plant leaf extracts

Fresh healthy plants of Barleria noctiflora were collected with root and shade dried for 8-10 days and grinded into powder. The air-dried and powdered plant materials were taken in different amber coloured bottles, $100 \mathrm{~g}$ dry powder sample was extracted with $80 \%$ ethanol at $55^{\circ} \mathrm{C}$ for 24 hours in soxhlet apparatus. Solvent elimination was done at room temperature and stored.

\section{Preparation of Drug}

The plant material was shade dried and pulverized. Methanol extract of the coarsely powdered material was prepared by employing Soxhlet method. The extract was concentrated and stored in brown bottles for future use. 
Free radical scavenging activity on DPPH

The antioxidant activity of the sample was determined in terms of hydrogen donating or radical scavenging ability, using the stable radical DPPH, according to the method of Blois (1958). The sample extracts at various concentrations (100 $500 \mu \mathrm{g})$ were taken and the volume was adjusted to $100 \mu \mathrm{l}$ with methanol. $5 \mathrm{ml}$ of $0.1 \mathrm{mM}$ methanolic solution of DPPH was added and allowed to stand for $20 \mathrm{~min}$ at $27^{\circ} \mathrm{C}$. The absorbance of the sample was measured at $517 \mathrm{~nm}$.

Percentage radical scavenging activity of the sample was calculated as follows:

$\% \mathrm{DPPH}$ radical scavenging activity $=$ (control OD-sample OD / control OD) $\times 100$

The analysis was performed in triplicate. The sample concentration providing $50 \%$ inhibition $\left(\mathrm{IC}_{50}\right)$ under the assay condition was calculated from the graph of inhibition percentage against sample concentration.

\section{In vitro Anti- inflammation activity}

Inhibition of protein denaturation: The reaction mixture $(0.5 \mathrm{ml})$ consisted of $0.45 \mathrm{ml}$ bovine serum albumin (5\% aqueous solution) and $0.05 \mathrm{ml}$ of the sample extract $(100-500 \mu \mathrm{g} / \mathrm{ml})$. $\mathrm{pH}$ was adjusted to 6.3 using a small amount of $1 \mathrm{~N} \mathrm{HCl}$. The samples were incubated at $37^{\circ} \mathrm{C}$ for $20 \mathrm{~min}$ and then heated at $57^{\circ} \mathrm{C}$ for $3 \mathrm{~min}$. After cooling the samples, $2.5 \mathrm{ml}$ phosphate buffer saline ( $\mathrm{pH}$ 6.3) was added to each tube. Turbidity was measured spectrophotometrically at $660 \mathrm{~nm}$. For control tests $0.05 \mathrm{ml}$ of distilled water was used instead of extracts while product control tests lacked bovine serum albumin. The percentage inhibition of protein denaturation was calculated as follows.

\section{Percentage inhibition $=$ 100-((O.D of test - O.D of product control)/ O.D of Control) x 100}

In vitro anti- inflammation activity of the selected samples were determined by inhibition of protein denaturation experiment and inhibition of $\alpha$ amylase studies. The $\mathrm{IC}_{50}$ value was defined as the concentration of the sample extract to inhibit 50\% of protein denaturation under assay condition.

\section{Proteinase inhibitory activity}

The reaction mixtures $(2.0 \mathrm{ml})$ contained $0.06 \mathrm{mg}$ trypsin, $1.0 \mathrm{ml}$ of $25 \mathrm{mM}$ tris - $\mathrm{HCl}$ buffer $(\mathrm{pH}-$ $7.4)$ and $1.0 \mathrm{ml}$ aqueous solution of the sample extract $(100-500 \mu \mathrm{g} / \mathrm{ml})$. The mixtures were incubated at $37^{\circ} \mathrm{C}$ for $5 \mathrm{~min}$ then $1.0 \mathrm{ml}$ of $0.8 \%$ $(\mathrm{w} / \mathrm{v})$ casein was added. The mixtures were incubated for an additional $20 \mathrm{~min} .2 .0 \mathrm{ml}$ of $70 \%$ $(\mathrm{v} / \mathrm{v})$ perchloric acid was added to terminate the reaction. The cloudy suspension was centrifuged. Absorbance of the supernatant was read at $280 \mathrm{~nm}$ against buffer as blank. The percentage of inhibition was calculated as follows.

$$
\begin{aligned}
& \text { Percentage inhibition }= \\
& 100-((\text { O.D of test }- \text { O.D of product control }) / \\
& \text { O.D of Control }) \times 100
\end{aligned}
$$

The $\mathrm{IC}_{50}$ value was defined as the concentration of the sample extract to inhibit $50 \%$ of protein denaturation under assay condition. (Shravan Kumar et al., 2011).

\section{Results and Discussion}

\section{The in vitro antioxidant potential}

Oxidative stress, the consequence of an imbalance of pro-oxidants and antioxidants in the organisms, is gaining recognition as a key phenomenon in chronic illness like inflammatory and heart diseases, hypertension, and some forms of cancer (Oh, 2001 and Zeynep et al., 2007). Plant based, antioxidant rich foods traditionally formed the major part of the human diet, and plant based dietary antioxidants are hypothesized to have an important role in maintaining human health (Benzie, 2013).

\section{Free radical scavenging activity on DPPH}

DPPH (1, 1-diphenyl-2-picrylhydrazyl) is a stable free radical and accepts an electron or hydrogen radical to become a stable diamagnetic molecule yellow-coloured diphenylpicrylhydrazyl (Soares et al., 1997; Kumaran and Karunakaran, 2007). The invitro antioxidant potential measured by $\mathrm{DPPH}$ inhibition assay method, Alcoholic extracts of aerial parts of ethanol extract of aerial parts of Barleria noctiflora is $34.11 \%$ to $87.55 \%$ and root is $24.81 \%$ to $79.86 \%$. The DPPH (1,1-diphenyl-2-picrylhydrazyl) radical scavenging activity of Barleria noctiflora is given in Table 1 . This activity was increased by increasing concentration of the sample extract. The $\mathrm{IC}_{50}$ value of alcoholic extracts of aerial parts of the Barleria noctiflora aerial parts extract shows $84.84 \pm$ $1.15 \mu \mathrm{g} / \mathrm{ml}$ and $101.39 \pm 1.18 \mu \mathrm{g} / \mathrm{ml}$ in root, compared with the standard ascorbic acid (3.76 \pm 0.07 ), which is a well-known antioxidant (Table :2). A higher DPPH radical scavenging activity is associated with a lower $\mathrm{IC}_{50}$ value (Daya and Mishra, 2012). The reduction capability of DPPH radical is determined by the decrease in absorbance at $516 \mathrm{~nm}$ induced by antioxidants. It has been found that cysteine, glutathione, ascorbic acid, tocopherol, flavonoids, tannins, and aromatic amines ( $\mathrm{p}$-phenylenediamine, $\mathrm{p}$-aminophenol, etc.), reduce and decolorize DPPH by their hydrogen donating ability (Blois, 1958; Yokozawa et al., 1998). The antioxidative effect is mainly due to phenolic compounds, such as phenolic acids, and phenolic diterphenes (Shahidi et al., 1992). The antioxidant activity of phenolic compounds is mainly due to their redox properties, which can play an important role in absorbing and neutralizing free radicals, quenching singlet and triplet oxygen, or decomposing peroxides (Osawa, 1994). For the measurements of the reductive ability, it has been found that the $\mathrm{Fe}^{3+}, \mathrm{Fe}^{2+}$ transformation occurred 
in the presence of extract samples which were postulated previously by Oyaizu (1986).

Sangilimuthu Alagar Yadav et al., (2012) evaluated the antioxidant activity of defatted ethanol extract of Barleria noctiflora leaf and root using in-vitro models. DPPH radical scavenging activity, ferrous reducing power, $\mathrm{Fe}^{2+}$ chelating activity assay, nitric oxide radical scavenging activity, $\mathrm{ABTS}^{+}$radical cation decolourisation assay, superoxide anion and hydrogen peroxide radical scavenging activities were studied. This study clearly showed good antioxidant capacity in DPPH radical scavenging assay, when compared to other in vitro models and the $\mathrm{IC}_{50}$ value were found to be $101 \mu \mathrm{g} / \mathrm{mL}$ in root extract of B. noctiflora.

\section{In vitro Anti- inflammation activity}

Inflammatory diseases like psoriasis, eczema, dermatitis, etc. require topical treatment to get relief from inflammation conditions associated with these diseases. Now a day herbal products are in good demand. The potential of Barleria in curing inflammation is well recorded in ancient texts. Studies done by other workers have validated the traditional use of the plant in acute and sub-acute inflammations (Kawal et al., 2014).

\section{Protein Denaturation inhibiting activity}

Denaturation of proteins is the main cause of inflammation. As part of the investigation on the mechanism of the anti-inflammatory activity, ability of the extract to inhibit protein denaturation was studied. Denaturation of proteins is a welldocumented cause of inflammation and rheumatoid arthritis (Mizushima, 1966). Several antiinflammatory drugs have shown dose dependent ability to inhibit thermally induced protein denaturation (Grant et al., 1970).

Protein denaturation inhibiting activity of Barleria noctiflora is represented in the Table3. Percentage activity in ethanol extract aerial parts of Barleria noctiflora is $4.82 \pm 0.69$ to $54.51 \pm 0.58$ and in extract of root $5.03 \pm 1.08$ to $49.28 \pm 2.37$. This activity is noticed in increasing concentration of extract from $100 \mu \mathrm{g}$ to $500 \mu \mathrm{g}$. The $\mathrm{IC}_{50}$ values of aerial parts $163.94 \pm 0.93 \mu \mathrm{g} / \mathrm{ml}$, root $188.17 \pm 7.50 \mu \mathrm{g} / \mathrm{ml}$, which is compared with the standard aspirin 51.10 $\pm 1.57 \mu \mathrm{g} / \mathrm{ml}$ (Table4).

\section{Proteinase inhibiting activity}

Result from Table 5 stated that a significant increasing percentage of activity in increasing concentration of sample extracts. Percentage of activity in ethanolic extract of Barleria noctiflora aerial parts is $9.68 \pm 4.02$ to $55.74 \pm 0.20$, in root $6.09 \pm$ 1.68 to $55.80 \pm 2.18$. The $\mathrm{IC}_{50}$ values of the Barleria noctiflora aerial parts $87.80 \pm 0.90 \mu \mathrm{g} / \mathrm{ml}$ root extract $88.13 \pm 3.05 \mu \mathrm{g} / \mathrm{ml}$ which is compared with the standard aspirin $41.84 \pm 0.10 \mu \mathrm{g} / \mathrm{ml}$ (Table : 6). Both aerial parts and root $B$. noctiflora shows a significant protein inhibiting activity.

Table 1. In vitro DPPH radical scavenging activity of Barleria noctiflora L.f.

\begin{tabular}{|c|c|c|c|}
\hline Sample & Concentration $(\mu \mathrm{g})$ & Percentage activity (\%) & $\begin{array}{c}\mathrm{IC}_{50} \\
(\mu \mathrm{g} / \mathrm{ml})\end{array}$ \\
\hline \multirow{5}{*}{ Aerial parts } & 100 & $34.11 \pm 1.08$ & \multirow{5}{*}{$84.84 \pm 1.15$} \\
\hline & 200 & $62.84 \pm 5.45$ & \\
\hline & 300 & $81.17 \pm 0.85$ & \\
\hline & 400 & $85.34 \pm 0.00$ & \\
\hline & 500 & $87.55 \pm 0.14$ & \\
\hline \multirow{5}{*}{ Root } & 100 & $24.81 \pm 1.11$ & \multirow{5}{*}{$101.39 \pm 1.18$} \\
\hline & 200 & $47.77 \pm 1.54$ & \\
\hline & 300 & $60.94 \pm 2.36$ & \\
\hline & 400 & $71.55 \pm 0.23$ & \\
\hline & 500 & $79.86 \pm 1.74$ & \\
\hline
\end{tabular}

Values are means of three independent analyses of the extract \pm standard deviation $(n=3)$

Table 2. Invitro DPPH radical scavenging activity of standard Ascorbic acid

\begin{tabular}{cccc}
\hline Sample & $\begin{array}{c}\text { Concentration } \\
(\boldsymbol{\mu g})\end{array}$ & Percentage activity $(\mathbf{\%})$ & $\begin{array}{c}\mathbf{I C}_{\mathbf{5 0}} \\
(\boldsymbol{\mu g} / \mathbf{m l})\end{array}$ \\
\hline \multirow{4}{*}{ Ascorbic acid } & 2 & $7.42 \pm 0.27$ & \\
& 4 & $17.84 \pm 0.40$ & \\
& 6 & $32.40 \pm 0.33$ & $3.76 \pm 0.07$ \\
& 8 & $39.78 \pm 0.11$ & \\
\hline
\end{tabular}

Values are means of three independent analyses of the extract \pm standard deviation $(\mathrm{n}=3)$

Table 3. Protein Denaturation inhibiting activity of Barleria noctiflora L.f.

\begin{tabular}{cccc}
\hline Sample & Concentration $(\boldsymbol{\mu g})$ & Percentage activity $(\mathbf{\%})$ & $\begin{array}{c}\mathbf{I C}_{\mathbf{5 0}} \\
(\boldsymbol{\mu g} / \mathrm{ml})\end{array}$ \\
\hline \multirow{3}{*}{ Aerial parts } & 100 & $4.82 \pm 0.69$ & \\
& 200 & $14.53 \pm 0.48$ & \\
& 300 & $29.05 \pm 0.58$ & $163.94 \pm 0.93$ \\
& 400 & $42.05 \pm 0.35$ & \\
\hline
\end{tabular}




\begin{tabular}{cll}
\hline Root & 200 & $16.52 \pm 1.08$ \\
& 300 & $24.57 \pm 0.75$ \\
& 400 & $32.76 \pm 1.14$ \\
& 500 & $49.28 \pm 2.37$ \\
\hline
\end{tabular}

Values are means of three independent analyses of the extract \pm standard deviation $(\mathrm{n}=3)$

Table. 4. Protein Denaturation inhibiting activity of standard Aspirin

\begin{tabular}{llll}
\hline Sample & Concentration $(\boldsymbol{\mu g})$ & Percentage activity $(\mathbf{\%})$ & $\begin{array}{c}\mathrm{IC}_{\mathbf{5 0}} \\
(\boldsymbol{\mu g} / \mathbf{m l})\end{array}$ \\
\hline \multirow{4}{*}{ Aspirin } & 25 & $13.01 \pm 0.70$ & \\
& 50 & $30.08 \pm 2.54$ & \\
& 200 & $48.78 \pm 3.66$ & \\
& 250 & $66.67 \pm 2.54$ & \\
\hline
\end{tabular}

Values are means of three independent analyses of the extract \pm standard deviation $(\mathrm{n}=3)$

Table 5. Proteinase inhibiting activity of Barleria noctiflora L.f.

\begin{tabular}{cccc}
\hline Sample & Concentration $(\boldsymbol{\mu g})$ & Percentage activity $(\mathbf{\%})$ & $\begin{array}{c}\mathbf{I C}_{\mathbf{5 0}} \\
(\boldsymbol{\mu g} / \mathbf{m l})\end{array}$ \\
\hline \multirow{4}{*}{ Aerial parts } & 100 & $9.68 \pm 4.02$ & \\
& 200 & $21.96 \pm 1.25$ & $87.80 \pm 0.90$ \\
& 300 & $33.03 \pm 1.18$ & \\
\multirow{3}{*}{ Root } & 400 & $46.19 \pm 0.81$ & \\
& 100 & $55.74 \pm 0.20$ & \\
& 200 & $6.09 \pm 1.68$ & \\
& 300 & $23.11 \pm 4.19$ & \\
& 400 & $33.43 \pm 1.51$ & \\
\hline
\end{tabular}

Values are means of three independent analyses of the extract \pm standard deviation $(n=3)$

Table 6. Proteinase inhibiting activity of standard Aspirin

\begin{tabular}{cccc}
\hline Sample & Concentration $(\boldsymbol{\mu g})$ & Percentage activity (\%) & $\begin{array}{c}\mathbf{I C}_{\mathbf{5 0}} \\
(\boldsymbol{\mu g} / \mathbf{m l})\end{array}$ \\
\hline \multirow{4}{*}{ Aspirin } & 25 & $14.15 \pm 0.09$ & \\
& 50 & $16.22 \pm 0.12$ & \\
& 150 & $30.73 \pm 0.15$ & $41.84 \pm 0.10$ \\
& 200 & $47.59 \pm 0.13$ & \\
\hline
\end{tabular}

Values are means of three independent analyses of the extract \pm standard deviation $(n=3)$

\section{Conclusion}

The present investigation examined the antioxidant potential of various extracts of Barleria noctiflora by in-vitro methods. The antioxidant activity was determined by DPPH activity. The in-vitro studies clearly showed that the ethanol extracts of sample has significant antioxidant activity. These in-vitro assays indicate that these plant extracts are a better source of natural antioxidant, which might be helpful in preventing the progress of various oxidative stresses. The in-vitro anti-inflammatory activity conducted Protein Denaturation inhibiting activity and Proteinase inhibiting activity. The result indicates the selected plants have better activity against inflammation.

\section{References}

1. Athar, Kosmulalage, Kalhari, and Radhika. "Chemical constituents of Barleria prionitis and their enzyme inhibitory and free radical scavenging activities". Phytochem. Lett 2 (2009):37-40.

2. Benzie. "Evolution of dietary antioxidants". Comp. Biochem. Physiol. A Mol. Integ. Physiol. 136 (2003): 113126.
3. Blois. "Antioxidant determinations by the use of a stable free radical”. Nature 26 (1958): 1199-1200.

4. Daya, Chothani, and Mishra. "In-vitro anti-oxidant activity of Ruellia tuberosa root extracts". Free Radicals and Antioxidants., 2.4 (2012) :38-44.

5. Duangporn Premjet, Siripong Premjit, Raden Arthur Ario Lenodo, and Sanro Tachibana. "Callus induction and determination of Iridoid glycosides from Barleria prionities Linn. Leaf explants". Australian J. Basic Appl. Sci. 4.9 (2010): 4461-4467.

6. Grant, Alburn, and Kryzanauskas. "Stabilization of serum albumin by anti-inflammatory drugs. Biochem”. Pharmacol., 19 (1970):715 -722.

7. Jassim, and Naji. "Novel antiviral agents: a medicinal plant perspective". J. Appl. Microbiol., 95(2003):412427.

8. Kawal, Vasisht, and Karan. "Acute and sub-acute anti-inflammatory evaluation with chemical studies on two species of an indigenous drug 'Barleria"'. J. Pharm Biomed Sci. 6.11 (2014): 63-68.

9. Kumaran, and Karunakaran. "In-vitro antioxidant activities of methanol extracts of five Phyllanthus 
species from India". LWT- Food Science and Technology40 (2007): 344-52.

10. Madhu, Chinnaiah, and Swamy. "Traditional herbal remedies to cure asthma in Adilabad district". IJPLS 1.4 (2010): 217-221.

11. Marles, and Farnsworth. "Antidiabetic plants and their active constituents". Phytomedicine 2 (1995):137189.

12. Mizushima. "Screening test for anti-rheumatic drugs". Lancet (1966) 2:443.

13. Oh. "Oxidative damages are critical in pathogenesis of reflux esophagitis implication of antioxidants in its treatment". Free Radic. Biol. Med. 30 (2001): 905915.

14. Osawa. "Novel natural antioxidants for utilization in food and biological systems. In: Uritani I, Garcia VV, Mendoza EM (Eds) Post harvest biochemistry of plant food-materials in the tropics". Japan Scientific Societies Press, Japan. (1994), 241-251.

15. Oyaizu. "Studies on product of browning reaction prepared from glucose amine". Japanese J. Nutrition, 44(1986): 307-315.

16. Ranjit Singh, Rajasree, and Sankar. "Screening for anti-diabetic activity of the ethanolic extract of Barleria cristata seeds". Inter. J. Pharm. \& Life Sci. 3.10 (2012): 2044-2047.

17. Rashmi, Laxmivenkatesh, Nargund, and Kuntal Hazra. "Thienopyrimidines as novel antiinflammatory agents and antioxidants". Der. Chemical inica 2.2 (2011), 165- 171.

18. Robert, and Turner. "Screening Methods in Pharmacol”. (2009) 152-153.

19. Saima Jalil, Bozhanka Mikhova, Rilka Taskova, and Maya Mitova. "In-vitro anti-inflammatory effect of Carthamus lanatus L". Z. Naturforsch 58c (2003): 830832.

20. Sandhya Lakheda, Roopam Devalia, Umesh, Jain, Nilesh Gupta, Ajay Raghuwansi, and Neeraj Patidar. "Anti-inflammatory activity of Artocarpus heterophyllus bark”. Der. Pharmacia Sinica 2.2 (2011):127-130.

21. Sangilimuthu Alagar Yadav, Anitha Jabamalai Raj, and Sathishkumar. "In vitro antioxidant activity of Barleria noctiflora L. f." Asian pacific journal of tropical biomedicine, (2012):S716-S722.

22. Shahidi, Janitha, and Wanasundara. "antioxidants. CRC Critical Rev". Food Science and Nutrition. 32.1 (1992): 67-103
23. Shankar, and Yadav. "Revision of the genus Barleria (Acanthaceae) in India". Rheedea. 20.2 (2010): 81-130.

24. Shravankumar, Kishore, Siva kumar, and Sindhupriya. "In-vitro anti-inflammatory and antiarthritic activity of leaves of Physalis angulata L". Inter. J. Pharm. and Ind. Res.1.3 (2011):211-213.

25. Soares, Dins, Cunha, and Ameida. "Antioxidant activity of some extracts of Thymus sygis". Free Radic Res. 26(1997): 469-78.

26. Suba, Murugesan, Kumararavelrajan, Mandal, and Saha. "Antiinflammatory, analgesic and antiperoxidative efficacy of Barleria lupulina Lindl. Extract". Phytother. Res. 19(2005): 695-699.

27. Suba, Murugesan, Arunachalam, Mandal, and Saha "Anti-diabetic potential of Barleria lupulina extract in rats”. Phytomed 11(2004):202-205.

28. Tripathi. "Essential of medical pharmacol". Pharmaceutical Technology 5 (2004): 257-259.

29. Wetson, Zorb, and John. "High phenotypic plasticity of Suaeda maritima observed under hypoxic conditions in relation to its physiological basis". Annals of Botany (2012) 1-10.

30. Yogamoorthi, and Sathya Priya. "Antiinflammatory and analgesic property of methanolic extract of Spinifex littoreus (Burm.f.) Merr." J. Environmental Biology 27.2 (2006): 271-273.

31. Yokozawa, Chen, Dong, Tanaka, Nonaka, and Nishioka. "Study on the inhibitory effect of tannins and flavonoids against the 1, 1-Diphenyl-2picrylhydrazyl radical". Biochem. Pharm. 56 (1998):213-222.

32. Zeng, Deng, and Zhang. "Cloning of Salt ToleranceRelated cDNAs from the Mangrove Plant Sesuvium portulacastrum L." J. Integrative Plant Biology 48.8 (2006): 952-957.

33. Zeynep, Kosar, and Kupeli. "Antioxidant, antiinflammatory, antinociceptive activities and composition of Lythrum salicaria L. extracts". J. Ethnopharmacol 110 (2007): 539-547.

\section{Cite this article as:}

M. S. Manjula and A. Saravana Ganthi. In-vitro antioxidant and anti-inflammatory potential of Ethanol extracts (root and aerial parts) of Barleria noctiflora. Annals of Plant Sciences 7.2 (2018) pp. 1997-2001.

do $\mathrm{http://dx.doi.org/10.21746/aps.2018.7.2.3}$ 